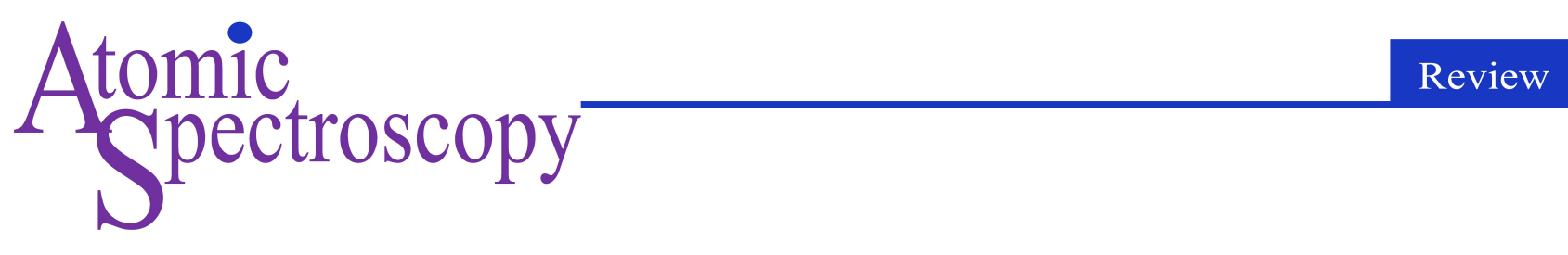

\title{
Inductively Coupled Plasma Mass Spectrometry for Metrometallomics: The Study of Quantitative Metalloproteins
}

\author{
Mengyun Pan, ${ }^{\text {a }}$ Yang Zang, ${ }^{\text {a,b }}$ Xirui Zhou, ${ }^{\text {a }}$ Yanli Lu,,${ }^{\text {a,b }}$ Jinping Xiong, ${ }^{\text {b }}$ Hongmei Li, ${ }^{\text {a }}$ and \\ Liuxing Feng a,* \\ ${ }^{\text {a }}$ Division of Chemical Metrology and Analytical Science, National Institute of Metrology, Beijing 100029, P.R. China \\ ${ }^{\text {b }}$ College of Material Science and Technology, Beijing University of Chemical Technology, Beijing 100029, P.R. China
}

Received: March 16, 2021; Revised: April 05, 2021; Accepted: April 05, 2021; Available online: April 15, 2021.

DOI: $10.46770 / A S .2021 .104$

ABSTRACT: The emerging field of metrometallomics refers to the qualitative and quantitative measurement of metallic analytes in the metrological sciences. Inductively coupled plasma mass spectrometry (ICP-MS) has the merits of multi-elemental quantification with very low detection limits. It has been applied for the quantification of peptides and proteins by measuring the concentration of certain elements, which is a very important applications area in metrometallomics. This review showcases the application of ICP-MS on the quantification of metalloproteins through the quantification of protein-bound metal/metalloid elements, intrinsic metal $/$ metalloid elements, or labeled metal/metalloid elements. The results of study also suggest that metrometallomics can be a useful tool in the development of certified reference materials of metalloproteins.

\section{INTRODUCTION}

Metallomics aims to provide a systematic understanding of the metal uptake, trafficking, and the role of and excretion in the biological systems. ${ }^{1,2}$ It focuses on the systematic study of the metallome and the interactions and functional connections of metal ions and their species with genes, proteins, metabolites and other biomolecules within the organisms. ${ }^{3,4}$ Here we propose "metrometallomics" as a branch of metallomics, which is defined as the measurement activities involved for metallic analytes with metrological strategies, including the establishment of reference methods with uncertainty evaluation, certified reference material (CRM) development, and their application in the life sciences, environmental sciences, etc. In the life science area, the current trend of metrometallomics research is towards the development of absolute quantitative strategies for the determination of the metaltransport protein and the metalloenzymes. The metal-transport protein delivers the metal ions directly to the target protein via specific protein-protein interactions, and the metal ions are generally coordinated with the oxygen, nitrogen or sulfur atoms of the amino acid residue on the polypeptide chain. Metalloenzymes contain metal cofactors that catalyze basic chemical reactions, and an imbalance of metalloenzymes can lead to many diseases. As metalloproteins represent around $30 \%$ of the whole proteome, they have become increasingly significant in clinical diagnostics. ${ }^{5}$ Therefore, their quantification is absolutely critical in order to access the capacity of biomarkers in clinical applications, which involves determination of the amount of substance of the target analyte in a given sample. However, since there is a great risk of exchange, acquisition or loss of the metal during separation of the proteins, ${ }^{6}$ the analytical strategies of absolute quantification of the metalloproteins are essential and technically challenging.

Mass spectrometry (MS)-based quantitative strategies mainly include molecular MS (e.g., ESI-MS) and elemental MS (e.g., ICP-MS). Molecular MS (such as ESI-MS, MALDI-MS) using multiple-reaction monitoring (MRM) for peptide or protein quantification has been considered a promising high-throughput targeting protein quantification technology (common strategies are based on bottom-up and top-down) in many instances. ${ }^{7}$ The 


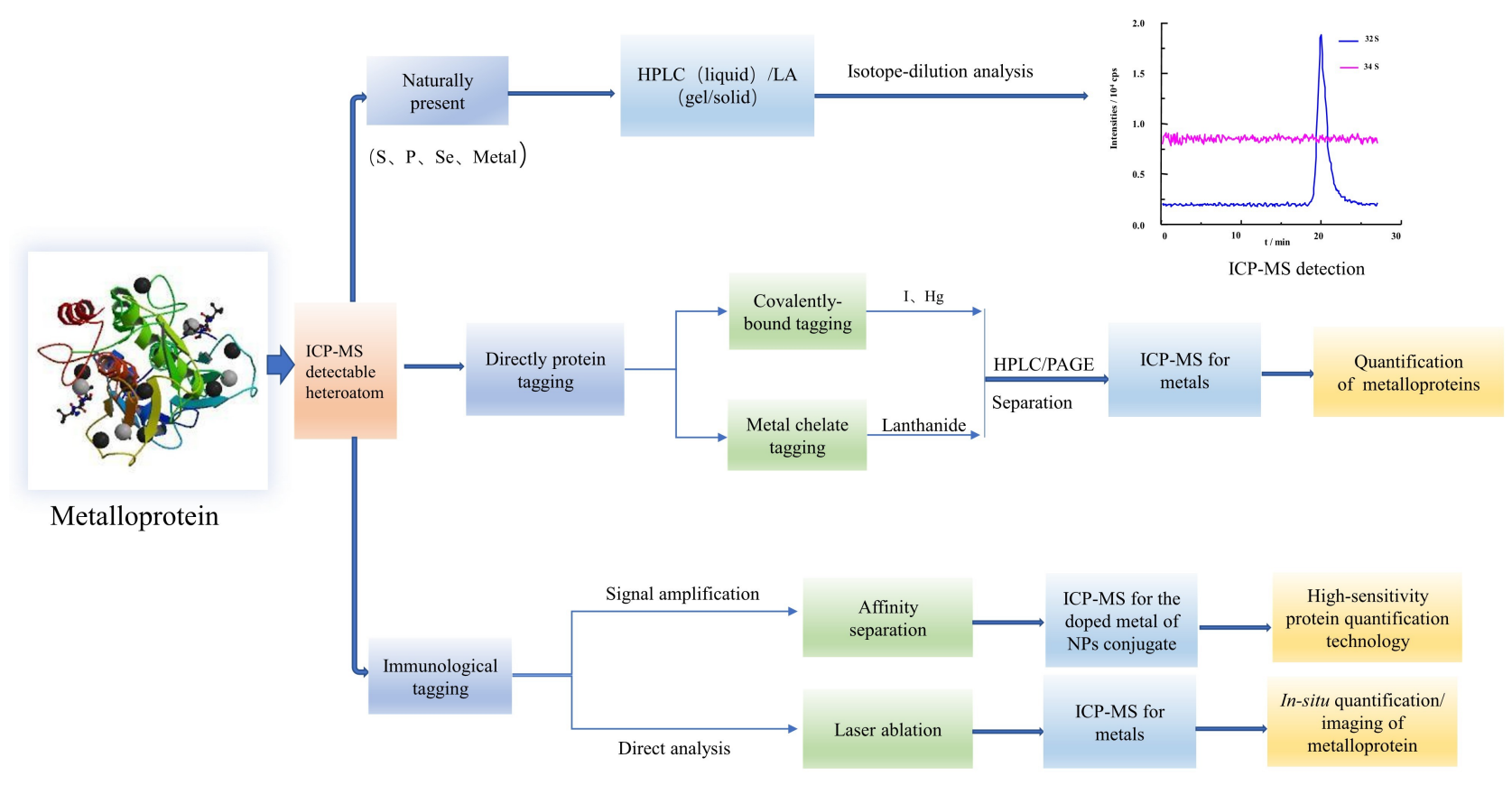

Fig. 1 Protein quantification strategies based on ICP-MS.

MRM technology selects the specific parent ion and product ion pair of the target protein to perform mass spectrometry analysis in order to eliminate the influence of the interfering ions to the greatest extent and thus, significantly improves the signal-to-noise ratio of the target peptide. This technology has the advantages of high sensitivity, good accuracy, and strong specificity. It is known as the "gold standard" for mass spectrometry quantification and is especially suitable for high-throughput verification of labeled proteins. The MRM technology can be combined with a variety of quantitative strategies. Proteomics experiments usually include a large number of separation and enrichment steps. Therefore, the earlier the internal standard is added, the less experimental error occurs. In addition, MRM is suitable for a variety of mass spectrometers, such as high-resolution mass spectrometers (QTOF, orbitrap, FT-ICR, which can distinguish mass differences in ppm) and low-resolution mass spectrometers, such as triple quadrupole mass spectrometers. ${ }^{8}$ However, some limitations of the MRM technology must be taken into account. Because of the signal intensity they provide, it is strongly affected by the sample matrix and the solvent used, and the ion sources used in MS are not inherently quantitative. On the other hand, it is well known that there is no linear relationship between the target peptide/protein concentration and the measured soft ion source signal intensity. Therefore, a specific standard (usually manually synthesized) of the target peptide/protein is required in order to obtain absolute quantification results. $^{7}$

ICP-MS as an elemental analysis tool uses a hard ionization source that dissociates proteins into elemental ions or molecular ions under $\sim 10,000 \mathrm{~K}$ in inductively coupled plasma (ICP). These elemental and molecular ions are introduced and filtered by the mass analyzer based on their mass-to-charge ratio $(\mathrm{m} / \mathrm{z})$ and are finally measured without significant spectral interference. This is particularly advantageous for quantitative purposes because of the excellent analytical features, such as low detection limits, wide linear dynamic range, high sensitivity, matrix-independent ionization and multi-elemental analysis..$^{9,10}$ Because of its hard ionization source, ICP-MS is a powerful technique which is able to provide absolute amounts of biomolecules in complex samples without the need for specifically targeted standards. ${ }^{11-12}$ Moreover, the use of stable isotopes, as non-radioactive tags for biomarker and for accurate biomolecule quantification with isotope-dilution analysis (IDA), is a great bonus of ICP-MS in tackling the longstanding problem of the absolute determination of proteins. ${ }^{13}$

IDA is an analytical technique based on the measurement of isotope ratios after the mixture of the spike (i.e. a known amount of an enriched isotope).${ }^{14}$ For an IDA study, the equilibration of the spike with the analyte is a prerequisite. Isotope dilution mass spectrometry (IDMS) has many unique advantages. First, the final results obtained by IDMS are independent of the drift of the instrumental signals and the matrix effects of the samples. Secondly, the results can provide definable uncertainty values and can achieve very high accuracy and precision with a mass spectrometer. Last but not least, once the complete isotope equilibration is achieved between sample and spike (e.g. full equilibration for solid samples can be reached after an appropriate digestion), any possible loss of the isotope-diluted analyte has no influence on the final results, because any fraction in the isotopediluted sample contains the same isotope ratio. Therefore, IDMS is regarded as one of the highly qualified primary methods. ${ }^{15}$ The detected heteroatoms may be naturally occurring, such as S, Se, P 
Table 1. Applications of Biomolecule Analysis by Using ICP-MS

\begin{tabular}{|c|c|c|c|c|}
\hline Elements & $\begin{array}{l}\text { Sample/ } \\
\text { Analyte }\end{array}$ & Technique & Analytical Performance & Reference \\
\hline $\begin{array}{l}\text { Mn, Co, Cu, } \\
\text { Se, }\end{array}$ & Human milk & SEC-ICP-MS & $\begin{array}{l}\text { Mn: LOD: } 2.81 \mu \mathrm{g} \mathrm{L}^{-1} \\
\text { Linear range: } 8.51 \sim 100 \mu \mathrm{g} \mathrm{L}^{-1} \\
\text { Co: LOD: } 3.39 \mu \mathrm{g} \mathrm{L}^{-1} \\
\text { Linear range: } 10.27 \sim 100 \mu \mathrm{g} \mathrm{L}^{-1} \\
\text { Cu: LOD: } 1.46 \mu \mathrm{g} \mathrm{L}^{-1} \\
\text { Linear range: } 4.43 \sim 100 \mu \mathrm{g} \mathrm{L}^{-1} \\
\text { Se: LOD: } 5.86 \mu \mathrm{g} \mathrm{L}^{-1} \\
\text { Linear range: } 17.75 \sim 100 \mu \mathrm{g} \mathrm{L}^{-1}\end{array}$ & 16 \\
\hline $\mathrm{Fe}, \mathrm{Cu}, \mathrm{Zn}, \mathbf{I}$ & Human milk & RP-HPLC-ICP-QQQ MS & $\begin{array}{l}\text { Mothers of pre-term (Fe: } 0.997, \mathrm{Cu}: 0.506, \mathrm{Zn}: 4.15 \text { and } \\
\text { I: } 0.458 \mathrm{mg} \mathrm{L}^{-1} \text { ) } \\
\text { Mothers of full-term (Fe: } 0.733, \mathrm{Cu}: 0.234, \mathrm{Zn}: 2.91 \text { and } \\
\text { I: } 0.255 \mathrm{mg} \mathrm{L}^{-1} \text { ) }\end{array}$ & 17 \\
\hline $\mathbf{S}$ & $\begin{array}{l}\text { Bamyloid Peptide } \\
\left(\mathrm{A} \beta_{42}\right)\end{array}$ & SEC-ID-ICP-MS & $\begin{array}{l}\mathrm{A} \beta: 0.763 \pm 0.0044 \mathrm{~g} \mathrm{~g}^{-1} \\
\text { LOD: } 140 \mathrm{pg} \mathrm{g}^{-1} \\
\text { Linear range:5 } 50 \mu \mathrm{g} \mathrm{g}^{-1}\end{array}$ & 18 \\
\hline $\mathbf{S}$ & $\begin{array}{l}\text { Proteomics in Snake } \\
\text { venoms }\end{array}$ & RP-HPLC-ID-ICP-QQQ MS & & 22 \\
\hline $\mathbf{S}$ & hGh & SEC-ID-ICP-MS & hGH: $18.86 \pm 0.77 \mathrm{mg} \mathrm{kg}^{-1}$ & 23 \\
\hline $\mathbf{S}$ & $\begin{array}{l}\text { Transferrin and } \\
\text { albumin in human } \\
\text { serum }\end{array}$ & GE-LA-ID-ICP-MS & $\begin{array}{l}\text { Linear range: } 1 \sim 400 \mu \mathrm{g} \mathrm{g}^{-1} \\
\text { Albumin:36.9 } \pm 1.55 \mathrm{mg} \mathrm{mL}^{-1} \\
\text { Transferrin:2.45 } \pm 0.06 \mathrm{mg} \mathrm{mL}^{-1}\end{array}$ & 19,20 \\
\hline Ca & Serum & ID-ICP-MS & & 24 \\
\hline $\mathbf{S}$ & SOD, BSA, MT-II & SEC-ICP-CC-MS & LOD for BSA, SOD, and MT-II are 8, 31, and $15 \mathrm{pmol}$ & 25 \\
\hline $\mathbf{F e}$ & Haemoglobin (HGB) & ID-ICP-MS & $\begin{array}{l}\text { HGB: } 115.3 \pm 2.4 \mathrm{mg} \mathrm{g}^{-1} \\
\text { LOD: } 1.0 \times 10^{-7} \mathrm{mg} \mathrm{g}^{-1} \\
\text { RSD }<3 \%\end{array}$ & 26 \\
\hline $\mathbf{F e}$ & Haemoglobin (HGB) & & HGB: $122.1 \pm 1.8 \mathrm{mg} \mathrm{g} \mathrm{g}^{-1}$ & 27 \\
\hline
\end{tabular}

and metals in proteins, selenoproteins, phosphoproteins and metalloproteins, respectively, or be intentionally bioconjugated as an elemental tag. However, those assets of ICP-MS as a reference technique also have their limitations for quantitative proteomic analysis. Due to the loss of structural information or identification from an atomized peptide or protein taking place in ICP, reliable analysis of the target proteins depends on the separation process in advance, such as liquid chromatography (LC), ${ }^{11}$ gel electrophoresis (GE), ${ }^{16,17}$ etc., in order to isolate the different compounds containing a detectable heteroatom before final measurement.

This article reviews the protein quantification techniques developed in ICP-MS (Fig. 1) in recent years and focuses on several techniques and methods for quantitative protein research using ICP-MS detectable heteroatoms, particularly metal-coded affinity tags (MECAT) and nanoparticles (NPs) immunoassay. What's more, because of the growing potential of direct analysis via laser ablation (LA) ICP-MS for metalloprotein quantification, the progress made with this methodology is also discussed.

\section{ABSOLUTE QUANTIFICATION OF METALLOPROTEINS BY USING ICP-MS}

\section{Naturally present elements (P, S, Se, and metals)}

At present, protein quantification by molecular MS is greatly limited because of the need for specific standards. Such standards must first be synthesized, then they have to be characterized and finally accurately certified, which leads to severe quantitative limitations. However, ICP-MS may achieve absolute protein quantification without the need of such specific standards due to its robust species-independent signal. There are some ICP-MS detectable heteroatoms ( $\mathrm{S}, \mathrm{P}, \mathrm{Se}$ and metals) naturally present in metalloproteins. All species in a sample need to be separated first since ICP-MS cannot distinguish the molecules of origin of the detectable element. Among the methods, the coupling of HPLC to ICP-MS appears to be one of the most common methods for protein analysis because of its ease of sample preparation and the simplicity of the interface. ${ }^{15-18}$ However, the hyphenated techniques incur some problems when a liquid chromatography column is coupled to ICP-MS with a nebulizer. GE-LA-ICP-MS has been increasingly employed for the quantification and characterization of metal-containing (e.g. $\mathrm{Zn}$ and $\mathrm{Fe}$ ) proteins, for example in brain or human serum. ${ }^{19-21}$ Due to the lack of suitable matrix-matched standard reference materials for GE-LA-ICP-MS, the accurate quantification of metal-containing proteins still poses important challenges. Some relevant applications of macro biomolecules analysis by using ICP-MS as the detector are given in Table 1.

In the ICP-MS determination of heteroatoms naturally occurring in proteins and peptides for protein quantification, the 
quality and reliability of the quantification results are less affected by isotope or chemical labeling of the proteins and the peptides. However, there are still many limitations in using heteroatoms to quantify proteins. ${ }^{22,23}$ Metals are not covalently bonded to the protein's moiety. It is not maintaining the integrity of the metalloproteins during the separation, which may result in loss of metal. Buffers and solutions for gel staining may be sources of metal contamination, and metal loss also occurs during the decolorization process. Such loss will result in crucial errors in protein quantification. Due to the low ionization efficiency of heteroatoms (such as phosphorus and sulfur which are covalently bonded to the protein's primary structure) and its susceptibility to severe spectral line interference, ${ }^{24,25}$ it is difficult to measure the heteroatoms by ICP-MS directly, and the measurement of heteroatoms is also interfered by polyatomic ions. ${ }^{26,27} \mathrm{In}$ fact, the use of the collision reaction cells and high-resolution ICP-MS instrumentation to remove polyatomic interferences may hinder the applicability of ICP-MS quantification in biological applications, usually requiring low limits of detection (LOD). ${ }^{28,29}$ In this sense, the introduction of tandem configurations into ICPMS instrumentation (ICP-QQQ) provided an efficient way for the elimination of polyatomic interferences and so for highly sensitive detection of non-metallic heteroatoms..$^{30}$ As a matter of fact, today, tandem ICP-MS enables highly sensitive quantification of S- and P-containing peptides and proteins. ${ }^{31}$

\section{Elemental labeling}

The sensitivity of ICP-MS for the detection of heteroatoms naturally present in proteins, even using tandem MS configurations, might not be sufficient for certain quantitative applications in biomedical research. In this sense, the trend for elemental labelling is to achieve higher selectivity and sensitivity in spite of the laborious and time-consuming labeling process. Usually, the label is easily ionized and has low background, which results in better sensitivity than for $\mathrm{S}, \mathrm{P}$, and $\mathrm{Se}^{32}$ By element labeling, peptides and proteins without heteroatoms can be detected and quantified by ICP-MS, which expands the analysis of proteins. ${ }^{33}$ Protein labeling can be done directly on the target protein or indirectly through its corresponding antibody (immunological strategy). The main limitations of the two strategies are dealing with excessive reagents, stoichiometric determination, and the possibility of generating undesirable products or fragments during the labeling process. Therefore, the labeling procedure must be properly characterized, and separation techniques are often employed to resolve potential interfering compounds in most proteomics applications. ${ }^{32-34}$

\section{Direct Protein Tagging (I, Hg, and Chelate complexes)}

As one of the most active functional groups in proteins, the sulfhydryl group (-SH) has unique physiological characteristics and plays an important role in protein stabilization, enzyme catalysis, heavy metal detoxification, and reactivity of the radicals. ${ }^{35}$ Because of the strong affinity of mercury and sulfur, organic mercury compounds are the most specific and sensitive reagents reacting with the sulfhydryl groups in peptides and proteins. The advantage of using monofunctional organic mercury ion $(\mathrm{R}-\mathrm{Hg})$ as a label is that it can react with a sulfhydryl group to provide a definite mass shift, especially a stable and characteristic non-radioactive isotope distribution. Guo et $a .^{36}$ studied the interaction between methylmercury and the - $\mathrm{SH}$ of peptides or proteins at room temperature and provided an alternative strategy to calculate the number of -SH and -S-S- involved. Compared with non-metallic elements, the method using mercury labeling has no spectral interference. However, since mercury has high ionization energy, only about $20 \%$ of the mercury is ionized in the plasma. In addition, mercury is highly toxic, which limits the practical application of mercury in quantitative protein analysis in ICP-MS. Although $96.6 \%$ of the proteins contain cysteine residues or disulfide bonds with the - $\mathrm{SH}$ groups, the reactivity of the $-\mathrm{SH}$ groups may vary depending on their location and the surrounding microstructure. ${ }^{37}$

Halogen, as a label for protein quantification, can be conjugated with the organic part of a protein. But currently, due to the high ionization energy, only iodine has been developed in the quantitative analysis of proteins. The principle is that a simple reagent $(\mathrm{NaI})$ can be oxidized to $\mathrm{I}^{+}$and react with the aromatic ring of the amino acid residues. Each tyrosine residue introduces two iodine atoms and each histidine residue introduces one iodine atom. Since iodination may be specific to more than one functional group of a protein, the non-specific iodination of tyrosine and histidine residues must be considered. ${ }^{38}$ More complex iodination reagents (such as pyridine) were used to iodide tetrafluoroborate, and the results showed that only the tyrosine residues in standard peptides are completely and specifically derivatized. ${ }^{39}$ The general disadvantage of iodine labeling is that the sensitivity of iodine in ICP-MS is not as good as that of metals (3-4 orders of magnitude lower than lanthanides), but it is more sensitive than non-metals naturally present in proteins (such as $\mathrm{P}$ or S). In addition, biological samples may contain a significant amount of natural iodine background. Waentig et al. ${ }^{40}$ examined the iodination of proteins, the entire proteome, and antibodies to analyze Western Blot membranes by LA-ICP-MS. Iodinated antibodies have been applied for the sensitive determination of transferrin in breast cancer cell lines using a novel immunoassay coupled to the ICPMS detection of iodine. Alonso-García ${ }^{41}$ revealed an iodine on the antibody iodination efficiency, the transferrin molar ratio was 27:1 which corresponds to the iodination of all the tyrosine residue present in the antibody.

So far, many commercially available reagents have been widely used in real samples. However, these methods are limited to the derivatization of one or two functional groups with a single element (Hg or I). In contrast, metal chelating tags show greater versatility because they potentially provide a combination of different metals and the functional groups. By using coordination 
ligands or dual-functional ligands containing detectable heteroatoms, metals detectable by ICP-MS can be introduced into proteins. Tetraazacyclododecane tetraacetic acid (DOTA) is a commonly used ligand. Lanthanide chelating tags containing reactive groups that allow binding to functional groups on biomolecules can be used to achieve specific lanthanide labeling (bio-binding) of biomolecules, which forms a covalent bond between the biomolecule and the chelating tag. In addition, the lanthanide-chelate label has very high thermodynamic stability. The use of lanthanide tags for protein labeling has many advantages. Compared with stable isotope reagents, lanthanide tags are cheaper, and there are more lanthanide elements available, which expands the selection range of protein metal labels. In addition, the lanthanide elements have high detection sensitivity, higher ionization efficiency, low background, and a large quantitative dynamic range, which makes lanthanide ideal tags for the quantitative analysis of protein by ICP-MS.

Despite the excellent features of lanthanides as labels for ICPMS detection, this method also has some disadvantages. First, the sensitivity is still limited by the number of metal ions that can be loaded into such chelates. Moreover, relatively high polarity of these derivatives makes their separation in reverse phase columns difficult in peptide/protein separations. In addition, metal atoms may be exchanged during the pretreatment process. The most important thing is that the quantified peptide must be able to achieve baseline separation. At the same time, other MS methods, such as ESI-MS, MALDI-TOF, must be used to identify their sequences, and the structure of proteins and peptides must be determined to achieve quantification. Whetstone et al. ${ }^{42}$ proposed a lanthanide-DOTA based element coded affinity tags (ECAT) method by avoiding the use of stable isotopes as mass labels, and a specific peptide containing a thiol group was labeled through the specific reaction with the thiol group. Jakubowski et al. ${ }^{43}$ used the bifunctional reagent 2-(4-isothiocyanophenyl)-1,4,7,10tetraazacyclododecane-1,4,7,10-tetraacetic acid (p-SCN-BnDOTA) as a label and measured two different proteins (bovine serum albumin and chicken egg white lysozyme). The proteins were labeled with elements, such as $\mathrm{Eu}, \mathrm{Tb}$, and $\mathrm{Ho}$, and the proteins were separated by sodium dodecyl sulfonate (SDS)PAGE. After the target protein was transferred to nitrocellulose, LA-ICP-MS was used for protein quantification. The obtained linear range of BSA was $0.015-15 \mathrm{pmol} \mathrm{g}^{-1}$ and the detection limit can be as low as $15 \mathrm{fmol} \mathrm{g}{ }^{-1}$. Yan et al. ${ }^{44}$ established a specific and efficient method for labeling intact proteins and achieved absolute quantification of the proteins with isotope dilution ICP-MS. 1, 4, 7, 10-tetraazacyclododecane-1, 4, 7-trisaceticacid-10maleimidoethylacetamide- europium (MMA-DOTA-Eu) was used as the marker to label lysozyme (lysozyme), insulin (insulin) and ribonuclease A (Rnase A). After the labeling conditions were optimized by ESI-MS, they were quantified by isotope dilution ICP-MS. The LODs of the three proteins obtained were 0.819 , 1.638 and $0.819 \mathrm{fmol} \mathrm{g}^{-1}$, respectively, and the recovery rate of this method could reach $97.9 \%$.

This method further verifies that the ICP-MS binding element labeling can well be applied to the absolute quantitative analysis of proteins. In order to improve the efficiency and specificity of protein metal labeling, Rappel and Schaumloffel ${ }^{37}$ optimized the acid anhydride bifunctional reagent (diethylenetriamine pentaacetic anhydride, Lu-DTPA) to label proteins, and the peptide reaction steps and reaction buffers were investigated to improve the labeling efficiency37. The specificity of the labeling reaction was verified by ESI-MS detection, and the recovery of the labeled peptide was $100 \%$ with a precision of $4.9 \%$. The LOD of the Lu-DTPA-labeled peptides can reach $179 \mathrm{pmol} \mathrm{g}^{-1}$, which is 4 orders of magnitude more sensitive than ICP-MS quantification by detecting sulfur and phosphorus atoms in proteins.

\section{Immunological Tagging}

Antibody-based immunoassay is another main tool for quantifying protein due to its good sensitivity, selectivity and throughput, especially the method based on enzyme-linked immuno sorbent assay (ELISA). In essence, suitable heteroatom-labeled antibodies can specifically recognize and bind to the target antigen protein or analyte even in complex matrices. However, traditional tags such as colorimetric tags and fluorescent tags are greatly affected with a complex biological matrix and poor dynamic range. Because of its good stability and great potential in multiplex analysis, elementtagged immunoassay may be a good choice for immunoassay. In 2001, Zhang et al. ${ }^{45}$ published an ICP-MS-based method for detecting proteins with lanthanide-labeled antibodies. The antigen is immunoreacted with a biotin-labeled antibody, which then binds to Eu-labeled streptavidin. Research over the next few years further demonstrated the potential of lanthanide-labeled antibodies for multiple protein analysis using ICP-MS. ${ }^{46}$ Due to the success of these experiments, various bioconjugation technologies and lanthanide chelation tags have been developed and verified to improve the sensitivity and multiplexing capabilities of these assays.

However, element-tagged immunoassay requires specific antibody design, and the sensitivity of the method of labeling antibodies with lanthanide-chelate complexes is affected by the reduction in the number of detectable heteroatoms of labeled antibodies. Tanner et $a l .{ }^{47}$ solved this problem by using polymerbased metal tags to label antibodies. These polymer tags bind up to 60 120 lanthanides per antibody and increased the final ICPMS sensitivity. Perez et al. $^{48}$ labeled specific monoclonal antibodies against four cancer biomarkers (CEA, sErbB2, CA 15.3 and CA 125) with different polymer-based lanthanides and separated, by size exclusion chromatography followed by ICP-MS detection, the antigen-antibody complex. The lanthanide loading in the polymer tag may be 30 times that of lanthanide-DOTA to improve the sensitivity and detection limit. This labeling method has a recovery rate ranging from $95 \%$ to $110 \%$ for all biomarkers studied, and the inter-assay and intra-assay accuracy is less than 
$8 \%$. However, polymer preparation is complicated, and the antibody cognitive ability is liable to be affected by a large number of polymer chains introduced. In fact, the concentrations of some target analytes in a real sample are extremely low, requiring the development of new signal amplification techniques for highly sensitive detection.

A recent alternative strategy was developed by using metalcontaining nanoparticles (NPs) as ICP-MS tags. In this strategy, if the exact number of metal atoms per nanoparticle and the stoichiometric number of the nanoparticle per antibody are known, the protein/peptide can be quantified without specific standards. However, the surface of nanoparticles is compatible with a large number of surface sealants and cleaning steps to prevent nonspecific adsorption. Yang et al. ${ }^{49}$ reported a protocol for the detection of tumor cells by using ICP-MS with lead sulfide nanoparticles (PbS NPs) as the elemental tag. Under the optimized conditions, the linear range of $800 \sim 40,000$ was obtained, and the relative standard deviation was $5.0 \%$. The proposed method has several advantages, including easy sample preparation, high sensitivity and selectivity. More importantly, this methodology could be extended to the detection of other cells based on their cellular biomarkers.

Gold nanoparticles (AuNPs) are most widely used due to their high sensitivity, good biocompatibility and low background in biological samples. Xiao et al..$^{50}$ proposed a simple, sensitive and specific assay for DNA by ICP-MS detection with AuNPs amplification and isothermal circular strand-displacement polymerization reaction (ICSDPR). Under the optimized condition, the proposed method could detect target DNA as low as $45 \mathrm{zmol}(8.9 \mathrm{fM}$ in $5 \mu \mathrm{L})$ in a relatively short time (about $4.5 \mathrm{~h}$ ) with good specificity, and the linear range of this method is $0.1 \sim 10,000$ pmol. Li et al. ${ }^{51}$ developed a high-sensitive detection of alpha-fetoprotein (AFP) by immunoassay ICP-MS strategy, which was based on tyramide signal amplification (TSA) and AuNPs labeling. Under the optimized conditions, the LOD of the developed method was $1.85 \mathrm{pg} \mathrm{mL}^{-1}$ with a linear range of $0.005 \sim 2 \mathrm{ng} \mathrm{mL}^{-1}$. The relative standard deviation (RSD) of seven replicates was $5.2 \%$. This strategy is highly sensitive and easy to operate and can be extended to the sensitive detection of other biomolecules in human serum. Ko et al. ${ }^{52}$ synthesized three different metal/dye-doped silica nanoparticles (SNPs) as probes for multiple detection of several clinical biomarkers. In the quantification, the doped metal of the SNP conjugate was measured by ICP-MS and the LOD was $0.35 \sim 77 \mathrm{ng} \mathrm{mL}^{-1}$ of different biomarkers.

\section{Direct quantification of proteins by LA-ICP-MS}

Laser ablation inductively coupled plasma mass spectrometry (LA-ICP-MS) has already been established as a powerful tool for the direct analysis of a wide variety of solid samples in life sciences. ${ }^{53-56}$ In LA-ICP-MS, sample aerosol is generated by LA and introduced into the plasma for vaporization, atomization and ionization. The elements on the surface of solid samples can be analyzed directly without sample pretreatment. Moreover, LAICP-MS can offer bioimaging with high spatial resolution in the low micrometer range, excellent LOD and the possibility of quantitative data. One of the main drawbacks of quantitative analysis by LA-ICP-MS, however, are sample-related "matrix effects" due to the difference in the interactions (e.g. absorptivity, reflectivity and thermal conductivity) between the laser beam and the different sample matrices. This brings noticeable changes in the mass of the analytes ablated per laser pulse in each case. An extensive overview about overcoming such limitations via internal standardization for LA-ICP-MS quantification has been published in several recent reviews. ${ }^{54,57,58}$

In the separation process of metalloproteins, such as chromatography and electrophoresis, the metal may be lost. In order to maintain the metal-protein binding, a non-denaturing gel separation method (natural PAGE) is recommended. The PAGE and LA-ICP-MS detection can be combined with elemental labeling after the tissue is incubated with an antibody that holds an elemental label. Among the external calibration strategies, the most commonly used one is the protein standard for electrophoretic separation or hydration of gels and the standard solutions for external calibration methods for the analysis of selenoproteins, phosphoprotein and metalloprotein. ${ }^{59}$ In order to overcome the problems caused by the incomplete or changeable ablation and/or ionization behavior of the analytes, the ${ }^{13} \mathrm{C}$ signal is generally used as the internal standard. ${ }^{60}$ It has also been reported to use the isotope dilution method to absolutely quantify protein by GE-LA-ICP-MS. Konz et al. ${ }^{19}$ reported for the first time the absolute quantification of natural transferrin (Tf) in human serum samples, separated by GE-LA-ICP-MS in combination with species-specific isotope dilution mass spectrometry (SSIDMS). However, isotopically enriched spikes are not available and metal losses in GE separation are the main limitations for SSisotope dilution GE-LA-ICP-MS. To overcome this problem, Feng et al. ${ }^{61}$ reported the determination of $\mathrm{Fe}$ transferrin and albumin in human serum by GE-LA-ICP-MS combined with species-unspecific isotope dilution. Compared with the alternative quantification methodologies, no calibration curves or speciesspecific spikes are necessary. The use of the LA-ICP-MS analysis approach based on such species-unspecific isotope dilution offers an important potential to achieve reliable, direct and simultaneous quantification of proteins after conventional 1D and 2D gel electrophoretic separations. The combination of immunoassay with LA-ICP-MS has also been reported. Gao et al. ${ }^{62}$ established a method using antibody-conjugated gold nanoparticles (AuNPs) to quantitatively image $\beta$-amyloid peptide $(A \beta)$ in the brains of $A D$ mice by LA-ICP-MS. The $A \beta$ antibody (anti-A $\beta$ ) was labeled with AuNPs to form the conjugate AuNPs-Anti-A $\beta$ that immunoreacted with $A \beta$ in mouse brain slices. Homogeneous brain slice matrix matching standards were used as the external calibrators for quantitative imaging of $\mathrm{Au}$. 
In recent years, great interest has been shown in studying the combined elemental and molecular distribution in biological tissues since LA-ICP-MS has emerged as one of the popular and powerful elemental imaging methodology for heteroatomcontaining proteins. ${ }^{63,64}$ However, because the use of LA-ICP-MS to detect biological tissues may have matrix effects during ablation, appropriate calibrations must be designed to compensate or mitigate this possible difference between samples and standards in order to obtain reliable quantitative data. ${ }^{65,66}$ The use of internal standards can help to correct the changes in the signal intensity of ectopic atoms for imaging and analyzing the matrix composition of the sample. Alternatively, an external appropriate internal standard can be used as a dry thin-layer aerosol or applied by depositing a uniform gold film on the surface of the tissue. ${ }^{63}$ In addition, an attempt was made to perform spatially resolved imaging of actual proteins by using exogenous tags for protein labeling and final LA-ICP-MS measurement. Different labeling reagents have been used for this exogenous immunoimaging, including metals (e.g. lanthanides), conventional dual-functional ligands, isotope-enriched polymer tags, and/or nanoparticles. Hutchinson et al. ${ }^{67}$ first reported the use of LA-ICP-MS for imaging of $\mathrm{Eu}$ and $\mathrm{Ni}$ coupled antibodies against the amyloid precursor protein and $A \beta$ in histological sections of a transgenic mouse model for Alzheimer's disease.

\section{Calibration for metalloprotein quantification by ICP-MS}

One of the attractions of quantification by elemental labeling is the simple calibration using only universal elemental standards. Conventional external calibration methods using such elemental standards can provide absolute protein quality by directly measuring the target heteroatoms. However, this method will be hindered by contamination, because in addition to the target protein, any substance that contains the detected element would contribute to the final heteroatom signal detected by ICP-MS. This is the main reason why this method is mainly applied to pure or highly purified samples. ${ }^{68}$ In most cases, two or more proteins need to be quantified in the same sample. In this case, if an ICPMS-based method is used, a reliable platform is required to ensure the pre-MS separation of each protein. It can be quantified by adding standards containing heteroatoms to the sample before chromatographic or electrophoresis separation. This method can determine the element response factor (peak area of the injected element per ng) of the instrument, which can be used to quantify the element content of other chromatographic peaks (i.e., certain element-containing proteins in the sample mixture). However, when using online reversed-phase LC-ICP-MS coupling, the influence of the change in the amount of organic solvent introduced during the gradient elution process on the sensitivity of the considered metal must be considered. At each time point of the gradient, the system should be calibrated. In fact, internal standards that show similar ionization behavior in plasma can be used to balance gradient effects. The most elegant solution is to add stable isotopes of the relevant metal after the column. This post-column isotope dilution technique cannot only compensate for the influence of the gradient, but also improve the precision and accuracy of the ICP-MS measurement because only the isotope ratio is determined instead of the absolute intensity. Therefore, the ability of ICP-MS to measure isotopes can combine ICP-MS element detection with isotope dilution procedures to quantify the elements with multiple stable isotopes. The method involves adding the isotope-enriched species of known concentration and the isotopic composition to the sample, so that the analyte can be quantified by measuring the isotope ratio. The added standard substance can be an isotope-enriched analogue of the target analyte (i.e. species-specific ID species), which can be added before chromatographic analysis to correct for sample loss or matrix effects. Alternatively, non-specific (universal) compounds (i.e. species-nonspecific ID speciation) containing enriched isotopes of the detected heteroatoms can be added online to the chromatographic eluent. Of course, the species-nonspecific ID method cannot correct the sample loss or incomplete recovery. However, it can quantify all the element species containing the target element using only quantitative analysis, because after adding spikes online and measuring the light/heavy isotope ratio, any possible signal changes during the chromatographic gradient can be corrected.

Another strategy is to combine the internal standard (IS) containing common elements with species non-specific ID quantification. As a result, the complexity of the isotope dilution calculation is reduced and the injection error is compensated. On the one hand, immunoassay quantification of element labeling is usually performed according to a typical immunoassay calibration curve. If the stoichiometric element is labeled and the antibody is known and controlled, no specific standards are needed to achieve quantification of the biomolecules.

The use of a certified reference material (CRM) is a very important calibration strategy for protein analysis. In the protein CRM development, although the ICP-MS approach was successfully demonstrated in the method development of protein quantification, its application on CRM certification has just been reported recently. Feng et al. ${ }^{18}$ first reported that the isotope dilution high-performance liquid chromatography mass spectrometry (ID-LC-MS) and high-performance liquid chromatography isotope dilution inductively coupled plasma mass spectrometry (HPLC-ID-ICP-MS) strategies were employed to certify the candidate $A \beta$ solution CRMs. These CRMs are primarily intended to be used for value assignment to secondary calibrators or CRMs with a clinical matrix, which will help in early diagnosis of AD.

\section{CONCLUSIONS}

In this review, we proposed metrometallomics as a branch of 
metallomics and showcased the application of ICP-MS in the quantification of metalloproteins as an example for the development of CRMs. The multiplicity of protein determination by ICP-MS is predictable and may constitute a valuable supplementary technique in the near future. In addition, the isotope dilution strategy can expand the multiplexing capabilities of ICPMS with high accuracy and small uncertainty. At present, basic research on the characterization of metal proteome in cells, tissues and organisms (such as microbial proteome) is also a clear field for ICP-MS guided proteomics. Therefore, we can imagine that further research will lead to using multiple quantitative analyses of proteins in the microarray, resorting to bioassays, and finally detection by LA-ICP-MS (and quantitative imaging work). By using ICP-MS certified peptides for the absolute quantification of the target protein, perhaps the application of ICP-MS in a wide range of molecular MS proteomics may become a common procedure. From an instrumental point of view, the recently introduced flow cytometer based on ICP-MS (which may allow the analysis of more than 100 different antibodies at the single cell level) may also provide a direct, innovative solution to the current situation.

\section{AUTHOR INFORMATION}

\section{Corresponding Author}

${ }^{*}$ L. X. Feng

Email address: fenglx@nim.ac.cn

Notes

The authors declare no competing financial interest.

\section{ACKNOWLEDGMENTS}

The authors received financial support from the National Natural Science Foundation (No. 12075230) and the National Key Research and Development Program (No. 2017YFF0205402).

\section{REFERENCES}

1. S. Mounicou, J. Szpunar, and R. Lobinski, Chem. Soc. Rev., 2009, 38, 1119-1138. https://doi.org/10.1039/b713633c

2. H. Haraguchi, J. Anal. At. Spectrom., 2004, 19, 5-14. https://doi.org/10.1039/b308213j

3. R. Ge and H. Sun, Sci. China Ser. B-Chem., 2009, 52, 2055-2070. CNKI:SUN:JBXG.0.2009-12-007

4. Y. F. Li, H. Z. Sun, C. Y. Chen, and Z. F. Chai, Metallomics. Beijing: Science Press, 2016. ISBN: 978-7-03-048241-9

5. J. Szpunar, Analyst, 2005, 130, 442-465. https://doi.org/10.1039/B418265K

6. C. L. Deitrich, A. Raab, B. Pioselli, J. E. Thomas-Oates, and
J. Feldmann, Anal. Chem., 2007, 79, 8381-8390. https://doi.org/10.1021/ac071397t

7. R. Aebersold and M. Mann, Nature, 2003, 422, 198-207. https://doi.org/10.1016/j.ics.2004.02.087

8. J. P. Lambert, M. Ethier, J. C Smith, and D. Figeys, Anal Chem., 2005, 77, 3771-3787. https://doi.org/10.1021/ac050586d

9. A. Tholey and D. Schaumloeffel, TRAC Trend Anal. Chem., 2010, 29, 399-408. https://doi.org/10.1016/j.trac.2010.01.010

10. F. Calderón-Celis, J. Proteomics, 2019, $198,11-17$. https://doi.org/10.1016/j.jprot.2018.11.010

11. L. Cid-Barrio, TRAC-Trend Anal. Chem., 2018, 104, 148-159. https://doi.org/10.1016/j.trac.2017.09.024

12. R. S. Amais, G. L. Donati, and M. A. Zezzi Arruda, TRAC Trend Anal. Chem., 2020, 133, 116094. https://doi.org/10.1016/j.trac.2020.116094

13. Z. R. Liu, X. T. Li, G. Y. Xiao, B. B. Chen, and M. He, TRAC-Trend Anal. Chem., 2017, 93, 78-101. http://dx.doi.org/10.1016/j.trac.2017.05.008

14. J. Bettmer and M. Montes Bayón, J. Proteomics, 2009, 72, 989-1005. https://doi.org/10.1016/j.jprot.2009.05.003

15. L. X. Feng, D. Zhang, J. Wang, and H. M. Li, Anal. Method., 2014, 6, 7655-662. https://doi.org/10.1039/c4ay00907j

16. M. Acosta, S. Torres, L. Marino-Repizo, L. D. Martinez, and R. A. Gil, J. Pharmaceut. Biomed., 2018, 158, 209-213. https://doi.org/10.1016/j.jpba.2018.06.003

17. V. de Oliveira Trinta, P. de Carvalho Padilha, and S. Petronilho, Food Chem., 2020, 326, 126978. https://doi.org/10.1016/j.foodchem.2020.126978

18. L. X Feng, Z. Z. Huo, J. P Xiong, and H. M Li, Anal. Chem., 2020, 92, 13229-13237. https://doi.org/10.19756/j.issn.0253-3820.191384

19. I. Konz, B. Fernandez, M. L. Fernandez, R. Pereiro, and A. Sanz-Medel, Anal. Chem., 2011, 83, 5353-5360. https://doi.org/10.1021/ac200780b

20. L. X. Feng, D. Zhang, D. R. Shen, J. Wang, and H. M Li, Anal. Chim. Acta, 2015, 884, 19-25. http://dx.doi.org/10.1016/j.aca.2015.05.009

21. D. Zhang, L. X. Feng, J. Wang, D. R. Shen, and J. P. Xiong, Chem. J. Chin. U., 2014, 35, 1889-1895. https://doi.org/10.7503/cjcu20140233

22. F. Calderón-Celis, L. Cid-Barrio, J. R. Encinar, and A. Sanz-Medel, J. Proteom., 2017, 164, 33-42. http://dx.doi.org/10.1016/j.jprot.2017.06.001

23. H. S. Lee, S. H. Kim, J. S. Jeong, Y. M. Lee, and Y.H. Yim, Metrologia, 2015, 52, 619-627. https://doi.org/10.1088/0026-1394/52/5/619

24. B. Han, M. Ge, H. Zhao, Y. Yan, J. Zeng, T. Zhang, W. Zhou, J. Zhang, J. Wang, and C. Zhang, DE GRUYTER., 2017 (aop). https://doi.org/10.1515/cclm-2017-0175

25. M. Wang, W. Feng, W. Lu, B. Li, B. Wang, M. Zhu, Y. Wang, H. Yuan, Y. Zhao, and Z. Chai, Anal. Chem., 2007,79, 9128-9134. https://doi.org/10.1021/ac071483t

26. M. Y. Pan, L. X. Feng, and H. M. Li, Chem. J. Chin. U., 2020, 41, 1983-1988. https://doi.org/10.7503/cjcu20200321

27. C. Brauckmann, C. Frank, D. Schulze, P. Kaiser, R. Stosch, and C. Swart, J. Anal. At. Spectrom., 2016, 31, 1846-1857. https://doi.org/10.1039/C6JA00028B

28. E. Bolea-Fernandez, L. Balcaen, M. Resano, and F. Vanhaecke, J. Anal. At. Spectrom., 2017, 32, 1660-1679. https://doi.org/10.1039/C7JA00010C 
29. O. Palacios, J. R. Encinar, D. Schaumloffel, and R. Lobinski, Anal. Bioanal. Chem., 2006, 384, 1276-1283. https://doi.org/10.1007/s00216-005-0286-0

30. S. D. Fernandez, N. Sugishama, J. R. Encinar, and A. Sanz-Medel, Anal. Chem., 2012, 84, 5851-5857. https://doi.org/10.1021/ac3009516

31. F. Calderon-Celis, S. Diez-Fernandez, J. M. Costa-Fernandez, J. R. Encinar, J. J. Calvete, and A. Sanz-Medel, Anal. Chem., 2016, 88, 9699-9706. https://doi.org/10.1021/acs.analchem.6b02585

32. O. Chahrour and J. Malone, Protein Pept. Lett., 2017, 24, 1-14. https://doi.org/10.2174/0929866523666161213094936

33. D. Kretschy, G. Koellensperger, and S. Hann, Anal. Chim. Acta, 2012, 750, 98-110. https://doi.org/10.1016/j.aca.2012.06.040

34. A. Sanz-Medel, M. Montes-Bayon, J. Bettmer,

M. L. Fernandez-Sanchez, and J. Ruiz Encinar, TRAC-Trend. Anal. Chem., 2012, 40, 52-63. https://doi.org/10.1016/j.trac.2012.07.020

35. M. Xu, L. Yang, and Q. Wang, Chem. Eur. J., 2012, 18(aop). https://doi.org/10.1002/chem.201200901

36. Y. Guo, L. Chen, L. Yang, and Q. Wang, J. Am. Soc. Mass Spectrom., 2008, 19, 1108-1113. https://doi.org/10.1016/j.jasms.2008.05.005

37. C. Rappel and D. Schaumloffel, Anal. Bioanal. Chem., 2009, 81, 380-393. https://doi.org/10.1021/ac801814a

38. N. Jakubowski, J. Messerschmidt, M. G. Anorbe, L. Waentig, H. Hayen, and P.H. Roos, J. Anal. At. Spectrom., 2008, 23, 1487-1496. https://doi.org/10.1039/b718074h

39. A. P. Navaza, J. Ruiz Encinar, A. Ballesteros, J. M. Gonzalez, and A. Sanz-Medel, Anal. Chem., 2009, 81, 5390-5399. https://doi.org/10.1021/ac9005606

40. L. Waentig, N. Jakubowski, H. Hayen, and P.H. Roos, J. Anal. At. Spectrom., 2011, 26, 1610-1618. https://doi.org/10.1039/c1ja10090d

41. F. J. Alonso-García, E. Blanco-González, and M. Montes-Bayón, Talanta, 2019, 194, 336-342. https://doi.org/10.1016/j.talanta.2018.10.020

42. P. A. Whetstone, N. G Butlin, T. M. Corneillie, and C. F Meares, Bioconjug. Chem., 2004, 15, 3-6. https://doi.org/10.1021/bc0341501

43. N. Jakubowski, L. Waentig, H. Hayen, J. Anal. At. Spectrom., 2008 , 23, 1497-1507. https://doi.org/10.1039/B800346G

44. X. Yan, M. Xu, L. Yang, and Q. Q. Wang, Anal. Chem., 2010, 82, 1261-1269. https://doi.org/10.1021/ac902163x

45. C. Zhang, F. B. Wu, Y. Y. Zhang, X. Wang, and X. R. Zhang, J. Anal. At. Spectrom., 2001, 16, 1393-1396. https://doi.org/10.1039/B106387C

46. C. Giesen, L. Waentig, U. Panne, and N. Jakubowski, Spectrochim. Acta B., 2012, 76, 27-39. https://doi.org/10.1016/j.sab.2012.06.009

47. S. D. Tanner, D. R. Bandura, O. Ornatsky, V. I. Baranov, M. Nitz, and M.A. Winnik, Pure Appl. Chem., 2008, 80, 2627-2641. https://doi.org/10.1351/pac200880122627

48. E. Perez, K. Bierla, G. Grindlay, J. Szpunar, J. Mora, and
R. Lobinski, Anal. Chim. Acta, 2018, 1018, 7-15. https://doi.org/10.1016/j.aca.2018.02.056

49. B. Yang, Y. Zhang, B. Chen, M. He, and B. Hu, Talanta, 2017, 167, 499-505. http://dx.doi.org/10.1016/j.talanta.2017.02.063

50. G. Xiao, B. Chen, M. He, X. Li, and B. Hu, Talanta, 2019, 202, 207-213. http://dx.doi.org/10.1016/j.talanta.2019.05.018

51. X. Li, B. Chen, M. He, G. Xiao, and B. Hu, Talanta, 2018,176, 40-46. http://dx.doi.org/10.1016/j.talanta.2017.08.007

52. J. A. Ko and H. B. Lim, Anal. Chim. Acta, 2016, 938, 1-6. http://dx.doi.org/10.1016/j.aca.2016.07.035

53. N. S. Mokgalaka and J. L. Gardea-Torresdey, Appl. Spectrosc. Rev., 2006, 41, 131-150. http://dx.doi.org/10.1080/05704920500510703

54. D. Pozebon, G. L. Scheffler, and V. L. Dressler, J. Anal. At. Spectrom., 2017,32, 890-919. https://doi.org/10.1039/C7JA00026J

55. K. A. Maloof, A. N. Reinders, and K. R. Tucker, Curr. Opin. Env. Sci. \& Health, 2020,18, 54-62. https://doi.org/10.1016/j.coesh.2020.07.005

56. D. Chew, K. Drost, J. H. Marsh, and J. A. Petrus, Chem. Geol., 2021, 559, 119917. https://doi.org/10.1016/j.chemgeo.2020.119917

57. D. Pozebon, G. L. Scheffler, V. L. Dressler, and M. A. G. Nunes, J. Anal. At. Spectrom., 2014, 29, 2204-2228. https://doi.org/10.1039/c4ja00250d

58. N. Miliszkiewicz, S. Walas, and A. Tobiasz, J. Anal. At. Spectrom., 2015, 30, 327-338. https://doi.org/10.1039/c4ja00325j

59. G. Ballihaut, F. Claverie, C. Pecheyran, S. Mounicou, R. Grimaud, and R. Lobinski, Anal. Chem., 2007, 79, 6874-6880. https://doi.org/10.1021/ac0709145

60. M. A. G. Nunes, M. Voss, G. Corazza, E. M. M. Flores, and V. L. Dressler, Anal. Chim. Acta, 2016, 905, 51-57. https://doi.org/10.1016/j.aca.2015.11.049

61. L. Feng, D. Zhang, J. Wang, D. Shen, and H. Li, Anal. Chim. Acta, 2015, 884, 19-25. http://dx.doi.org/10.1016/j.aca.2015.05.009

62. X. Gao, H. Pan, Y. Han, L.Feng, J. Xiong, S. Luo, and H. Li, Anal. Chim. Acta, 2021, 1148, 238197. https://doi.org/10.1016/j.aca.2020.12.072

63. J. S. Becker, J. Mass Spectrom., 2013, 48, 55-268. https://doi.org/10.1002/jms.3172

64. J. S. Becker, A. Matusch, and B. Wu, Anal. Chim. Acta, 2014, 835, 1-18. https://doi.org/10.1016/j.aca.2014.04.048

65. D. Hare, C. Austin, and P. Doble, Analyst, 2012, 137, 1527-1537. https://doi.org/10.1039/c2an15792f

66. I. Konz, B. Fernandez, M. L. Fernandez, R. Pereiro, H. Gonzalez, L. Alvarez, M. Coca-Prados, and A. Sanz-Medel, Anal. Bioanal. Chem., 2013, 405, 3091-3096. https://doi.org/10.1007/s00216-013-6778-4

67. R. W. Hutchinson, A. G. Cox, C. W. McLeod, P. S. Marshall, A. Harper, E. L. Dawson, and D. R. Howlett, Anal. Biochem., 2005, 346, 225-233. https://doi.org/10.1016/j.ab.2005.08.024

68. M. Wang, W. Y. Feng, Y. L. Zhao, and Z. F. Chai, Mass Spectrom. Rev., 2010, 29, 326-348. https://doi.org/10.1002/mas.20241 